\title{
DISCUSIONES
}

CRítTCA, Revista Hispanoamericana de Filosofia

Vol. XXII, No. 65 (agosto 1990): 73-92

\section{SOBRE JUSTIFICACIÓN Y VERDAD: RESPUESTA A LEÓN OLIVÉ}

LUIS VILLORO

Instituto de Investigaciones Filosóficas Universidad Nacional Autónoma de México

En varios trabajos León Olivé (1984, 1986, 1988) ha presentado comentarios críticos a algunas tesis de mi libro Creer, saber, conocer (1982), particularmente a la relación entre justificación objetiva y verdad. Como alternativa a las dificultades que encuentra en mi tesis, ha ofrecido otra propuesta teórica que conduce a un concepto nuevo de verdad.

"Justificación", “objetividad", "saber", "conocimiento", "realidad", "verdad", "racionalidad" pertenecen a una misma familia de conceptos. Ninguno se entiende sin referencia a los demás. Tanto las críticas de Olivé como su propia respuesta son una contribución seria para dilucidar mejor la relación entre esos conceptos. Merecen toda nuestra atención. Empecemos por examinar sus reparos a la noción de verdad como "adecuación" y al llamado "realismo metafísico".

\section{Verdad como adecuación}

Para despejar el camino, reconozcamos un error. En mi libro avancé una interpretación realista de la definición semántica de verdad como si fuera la única posible. Tiene razón Olivé en señalar que la definición de Tarski es neutra frente a la alter- 
nativa realismo-antirrealismo (1988, p. 161). Por sostener esa interpretación tengo una excusa: coincidía con mis preferencias teóricas y me parecía corresponder a la del propio 'Tarski. Aun así, debí señalar que no se deriva con necesidad de la definición semántica.

Otra omisión de mi parte: adhiero a la concepción de la verdad como "adecuación entre el entendimiento y la realidad", sin aclarar en qué sentido podría considerarla legítima. Ahora bien, esa concepción ha sido blanco de serias objeciones los últimos años. Creo sin embargo, que todas ellas afectan a una versión que entendería la "adecuación" al modo de una correlación entre dos entidades distintas y separables. Wittgenstein, en su teoría de la "figura" (Bild), es responsable de la formulación moderna más elaborada de esta versión. Pero creo que la concepción de la verdad como adaequatio expresa una intuición básica imprescindible: que la verdad no puede comprenderse como una relación intra-lingüística o intra-mental, sino que, en los enunciados verdaderos, alcanzamos una realidad extra-lingüística. Por desgracia, los nombres de "correspondencia"o "adecuación" sugieren una imagen engañosa: la comparación entre dos entidades previamente existentes: por un lado enunciados o creencias, por el otro, una realidad no afectada por ninguna creencia. Esta imagen supone dos ideas insostenibles: 1) admitir la posibilidad de conocer una realidad separada de todo sujeto; 2) concebir la "correspondencia" en analogía con la relación entre dos formas o estructuras cuyos elementos embonarían entre sí.

Pero cabría otra versión de la verdad como correspondencia que, sin aceptar esos supuestos, hiciera justicia a su intuición básica. Recordemos, primero, que lo que puede ser "verdadero" o "falso" no es el enunciado en cuanto acto de habla (Speechact) sino lo enunciado en él. "Decir la verdad no es una manera de decir: es decir algo verdadero" (P. Strawson, 1964, p. 33, sub. nos.). Lo dicho, lo enunciado en el "decir la verdad" es una situación objetiva (Sachverhalt, state of affairs) 
existente. Por ejemplo si el enunciado "la luna es brillante" es verdadero, entonces es un hecho que la luna es brillante; esto quiere decir que la situación objetiva enunciada es. Lo que hace verdadero al enunciado no es algo perteneciente al enunciarlo, sino el hecho de que algo existe. $\mathrm{Y}$ el hecho no es distinto a la situación objetiva existente. El hecho de que $p$ no es algo distinto a la situación enunciada en " $p$ ", es sólo la característica de existir de p. La misma situación objetiva puede existir realmente o ser solamente enunciada (creída, juzgada, mencionada). En el primer caso es un hecho. El hecho de que la situación objetiva exista realmente no convierte a la situación enunciada en imagen o figura $(B i l d)$ que pudiera compararse con ella, pues el hecho es la existencia real de $l a$ misma situación enunciada. No hay, en suma, dos entidades que comparar sino una sola que tiene, en un caso, existencia puramente enunciada, de origen lingüístico, y en el otro existencia real. Recordemos la antigua distinción entre "existencia objetiva" y "existencia formal". Podríamos decir que lo enunciado, en un enunciado verdadero, tiene "existencia objetiva" en cuanto enunciado y "existencia formal" en cuanto verdadero. Por lo tanto, si " $p$ " es verdadera, podemos entender por $p$ el hecho real que hace verdadera a " $p$ ", sin que ese hecho pueda compararse, de ningún modo, con " $p$ ", puesto que es lo mismo enunciado en " $p$ ".

Pero que la situación objetiva sea un hecho quiere decir que no es sólo una entidad lingüística, que no está "puesta", "constituida" en el acto de enunciarla, que su existencia no obedece a ese acto. Husserl expresaba esto al decir que entonces la situación objetiva está "dada por ella misma" (Selbstgegeben). La verdad sería la adecuación de lo significado con lo "dado por sí mismo". Pero no se trataría de una concordancia entre dos entidades diferentes sino del darse lo significado tal como es significado (1929, VIa. Investigación, cap. V). La noción de verdad como "correspondencia" sería una manera metafórica de indicar que la verdad se da sólo cuando una situación ob- 
jetiva enunciada o creída es, además, un hecho real, es decir "corresponde" a algo existente. Quizás, como piensa Strawson (1964, p. 32) conviniera abandonar de lleno la noción de "adecuación" o "correspondencia", para evitar equívocos. Pero entonces habría que reemplazarla por otra que recogiera sus dos ideas fundamentales: 1) el hecho que hace verdadero al enunciado no es una entidad lingüística; 2) ese hecho "corresponde" a una entidad enunciada, luego, lingüística. Me parece que las concepciones de la verdad propuestas como alternativas a la noción de "correspondencia" (verdad como coherencia, como consenso, etc.) no hacen plena justicia a esas dos ideas.

Quien siguiera esta versión de la teoría de la adecuación, no podría aceptar la reducción de la verdad a una relación intraconceptual, pero sí debería aceptar la idea recordada por Olivé de que la verdad no implica una comparación o correspondencia entre una entidad conceptual y una realidad "incontaminada" por conceptos.

\section{Realismo metafísico}

Olivé cree leer $(1984$, p. 80-88) en mi libro un "realismo metafísico". Hilary Putnam (1981, p. 49) ha definido ese tipo de realismo por tres note s: 1) "El mundo consiste en una totalidad fija de objetos independientes de la mente". Como veremos, "independiente de la mente" es un término ambiguo. Putnam no lo aclara pero, por el contexto, es de presumir que entiende por él algo así como "no afectado" por conceptos o enunciados. 2) "Sólo hay una descripción verdadera y completa de la 'manera cómo es el mundo" ". 3) La verdad implica una correspondencia entre signos lingüísticos y cosas "externas". Una doctrina que sostuviera esas tres proposiciones es tan claramente contradictoria que resulta sorprendente que Putnam dedique tantas páginas a refutarla. Esas tres proposiciones comprometen, en efecto, a aseverar la existencia de una realidad que, por definición (proposición 1), es independiente de toda aseve- 
ración, así como a aceptar la posibilidad de una descripción del mundo independiente de las condiciones subjetivas que hacen posible toda descripción (proposición 2). Ignoro quién podría sostener un "realismo" semejante.

En mi libro (1982) me incliné por una forma de realismo. De seguro no me detuve en distinguirlo de otras formas; soy responsable pues de los equívocos a que puede dar lugar. Con todo, no creo que pueda interpretarse mi postura en el sentido del "realimo metafísico" tal como Putnam lo define. De las tres proposiciones que lo caracterizan, la tercera se refiere a la versión simplista de la verdad como adecuación que acabo de discutir. En la primera proposición (la existencia de "objetos independientes de la mente") hay una ambigüedad que intentaré dilucidar más tarde. Todo realismo acepta la existencia independiente del mundo, pero no necesariamente la independencia respecto de la mente de los objetos pensados. Esta segunda proposición es contraria a la tesis central de Creer, saber, conocer. Una parte de mi argumentación para eliminar la verdad de las condiciones de "saber" consistió justamente en mostrar la imposibilidad de admitir una verdad absoluta que no sería concebida o aseverada por ningún sujeto (1982, p. 182 $3)$. Por otra parte, traté de mostrar que ningún sujeto puede juzgar de la verdad de sus creencias si no es mediante sus propias justificaciones. La admisión de una objetividad independiente del proceso de justificación sería contradictoria. Una cosa es sostener que un hecho enunciado tiene una existencia independiente de su enunciarlo (tesis de todo realismo) y otra que pueda ser un objeto independiente del enunciado (tesis contradictoria del llamado "realismo metafísico"). Permítaseme una cita de mi libro: "No afirmamos que _ $-s_{i}$ " $p$ " es verdaderael hecho p no exista con independencia de todo juicio, sino que no pucde ser juzgado, ni sabido, con independencia de todo juicio" (1982, p. 178).

Tampoco he sosienido la posibilidad de "una completa y verdadera descripción del mundo". Olivé, que ha leído con inte- 
ligencia mi libro, sabe que intenté demostrar cómo todo saber, por lo tanto toda descripción del mundo, está condicionada por las creencias básicas de una "comunidad epistémica" históricamente determinada. ¿Cómo podría entonces admitir una sola verdadera descripción del mundo? Olivé interpreta una frase mía como si afirmara que "El progreso del saber estriba en un acercamiento a la única completa y verdadera descripción acerca del mundo real" (1984, p. 88). Pero lo que yo escribí es algo distinto: "La verdad absoluta no es plenamente alcanzable por sujetos históricos; su acceso a ella siempre será parcial y estará limitado por condiciones fácticas. Sin embargo, la adecuación plena de nuestros juicios a la realidad es una idea regulativa de la razón a la que se aproxima progresivamente, en etapas sucesivas, el conocimiento de la especie" (1982, p. 195). El acceso a la verdad estará por lo tanto, siempre condicionado históricamente. La meta regulativa no es "alcanzar una única descripción verdadera del mundo", sino progresar en descripciones, condicionadas históricamente por cada comunidad epistémica, pero cada vez provistas de mejores garantías para alcanzar la realidad.

Coincido, pues, con Olivé en el rechazo de un "realismo metafísico" como lo entiende Putnam. La postura más razonable me parece la de un realismo (¿podríamos llamarlo "ontológico"?) que aceptara la existencia de un mundo común a todo sujeto, independiente ontológicamente, pero no describible ni cognoscible con independencia de todo sujeto. ¿No es ésta también la posición de Olivé? Así se desprende de frases como ésta: "Por mi parte considero que un genuino realismo debe aceptar que hay una realidad no contaminada por conceptualizaciones, es decir, independiente de todo marco conceptual. Pero igualmente debe rechazar la idea de que existe un único, verdadero y completo marco conceptual que ofrece la descripción correcta de la realidad" (1986, p. 155 y 1988, p. 171). El problema sería cómo concebir ese realismo. 


\section{"Realismo interno"}

Olivé sostiene un "realismo interno" que modifica en un punto importante el de Putnam. Veamos primero este último. Putnam caracteriza su realismo con dos ideas: 1) Los objetos no pueden concebirse más que "en el interior del esquema conceptual" de los sujetos; pero además "los objetos no existen independientemente de los esquemas conceptuales" (1981, p. 52). Notemos que Putnam pasa, sin argumento alguno, de "los objetos no pueden concebirse sin esquemas conceptuales" (lo cual es cierto) a "los objetos no existen sin esquemas conceptuales" (lo cual puede o no ser cierto según el sentido de "objetos", pero, en todo caso, no se deduce de la proposición anterior). Éste es un punto que discutiremos en el segundo apartado. 2) "La vendad es alguna especie de aceptabilidad racional (idealizada)" (1981, p. 49). Esta segunda tesis es lógicamente independiente de la primera. En efecto, de la dependencia de los objetos a conceptos no se sigue que la verdad sea una forma de "aceptabilidad" y no una forma de "adecuación", salvo si "adecuación" se define por la versión contradictoria que Putnam presta al "realismo metafísico".

Olivé sigue el realismo interno de Putnam con dos modificaciones importantes: 1) reemplaza la noción vaga de "esquemas conceptuales" por la de "marcos conceptuales", más precisa y a salvo, según Olivé, de las objeciones de Davidson. Si lo he entendido bien, cada "comunidad epistémica" estaría determinada por un "marco conceptual” específico. 2) Olivé se percata de que, en la posición de Putnam, tanto la realidad como la verdad sólo pueden darse en el interior de un marco conceptual. Por lo tanto, no se puede explicar el cambio de los marcos conceptuales ni, en mi terminología, el tránsito de una comunidad epistémica a otra (1986, p. 172, 1988, p. 156). Para explicar el cambio de marcos conceptuales, Olivé acepta que "hay una realidad no contaminada por conceptualizaciones, es decir, independiente de todo marco conceptual", aunque no exista un 
único marco conceptual susceptible de ofrecer la descripción correcta de esa realidad (1986, p. 171). Me parece que, en ese punto, el "realismo interno" tal como Olivé lo entiende coincide con mi propia postura.

Pero centremos el problema: frente a los argumentos de Putnam, ies posible admitir un mundo "tal como existe con independencia de cualquier sujeto que lo crea", para usar mi propia fórmula? (1982, p. 176). Todo depende de lo que se entienda por "independencia". Si se entendiera en el sentido dicl "realismo metafísico"de que habla Putnam, no sería posible. En efecto, supondría una realidad "independiente de todo concepto" que sólo podría ser descrita con un tipo de conceptos.-De la negación de esa proposición contradictoria Putnam pretende concluir que "los objetos no existen con independencia de esquemas conceptuales" (1981, p. 52). Esta proposición es verdadera si y sólo si "objeto" quiere decir "aquello que es el término de nuestros conceptos". Pero entonces es una tautología. Esa proposición no se concluye, en cambio, si "objeto" quiere decir "hecho o situación objetiva existente". En efecto, del hecho de que todo objeto deba concebirse mediante conceptos (enunciado tautológico) no se sigue que lo así concebido no exista con independencia de conceptos. Putnam confunde dos nociones elementales: dependencia noseológica y dependencia ontológica. De la primera no puede concluirse la segunda. De que una rosa no sea rosa más que si la nombro "rosa" no se sigue que no sea, sin que nadie la nombre "rosa". Lo que una cosa sea depende de nuestros esquemas conceptuales, que una cosa sea no depende de ninguno.

Si lo interpreto bien, Olivé no cae en el simplismo de Putnam. Critica mi postura porque cree leer en ella una versión de un "realismo metafísico". Pero ya indiqué que no pretendo sostener esa tesis. Olivé ofrece, en cambio, una versión realista más clara y convincente que la que yo había expuesto en mi libro. No puedo menos que aceptarla. Subrayemos sólo un punto. Olivé difiere de Putnam y coincide conmigo en que, para expli- 
car el cambio de marcos conceptuales, es menester admitir la existencia de una realidad independiente de todo marco conceptual. A la vez sostiene, con Putnam, que toda descripción de esa realidad se hace "en el interior" de un marco conceptual. Esas dos proposiciones no son contradictorias sólo si se distingue independencia ontológica de independencia noseológica. Para explicar tanto la coincidencia de todos los sujetos de una comunidad epistémica en un saber objetivo, como el paso de una comunidad epistémica a otra, debemos admitir tanto la independencia ontológica del mundo, como su dependencia noseológica. Creo que ésa es la tesis de Olivé aunque dicha con otras palabras. Creo también que expone mejor de lo que yo había hecho, mi propia convicción. No creo haberme equivocado, por lo tanto, como piensa Olivé, al sostener que "la mejor explicación de la coincidencia [de los juicios empíricos de los miembros de una comunidad epistémica] es la existencia real, independiente de los sujetos, de los hechos juzgados" (Villoro, 1982 , p. 181 y Olivé, 1986, p. 163), porque lo que califico de "independiente de todo sujeto" no son los objetos en tanto conocidos o juzgados, sino la existencia de los hechos juzgados, y me parece que, en este punto, Olivé debería coincidir conmigo. En cambio, en algunas frases de Olivé aún subsiste cierta ambigüedad. La admisión de "un mundo real común a todo sujeto" debe entenderse - dice (1986, p. 168)— como "mundo común a todo sujeto que comparta ese marco conceptual" y "mundo real" como "no independiente del marco conceptual". Tiene razón si "independiente" se entiende en un sentido noseológico, y "mundo" como el conjunto de "objetos conocidos o descritos", pero no la tiene si "independiente" tiene un sentido ontológico y "mundo" es simplemente la realidad que es.

\section{Verdad y justificación}

Regresemos ahora a la noción de verdad. Para explicar el cambio de marcos conceptuales y, a la vez, evitar la relativización 
de la verdad a comunidades históricamente determinadas, caben dos vías diferentes: Primera: No separar "verdad" de "justificación objetiva". La verdad se define como una forma de justificación. Cuando ésta se realiza en ciertas condiciones ideales, resulta común a toda comunidad epistémica y, por lo tanto, universal. Es la vía que sigue Olivé. Segunda: Distinguir entre "justificación objetiva" y "verdad". La verdad podría inferirse de la justificación cuando ésta cumple con ciertas condiciones, pero no coincide, por definición, con ninguna forma de justificación. Ambas vías son compatibles con el "realismo interno" tal como Olivé lo concibe. Las dos presentan ventajas e inconvenientes teóricos. Sólo podemos dirimir entre ellas si determinamos cuál postura suministraría un marco conceptual mejor para comprender los problemas que nos ocupan. Por las razones que aduciré, la segunda vía me parece la más aceptable.

Aunque las posiciones de Putnam, de Habermas y de Olivé presentan diferencias, coinciden en un punto: derivar la noción de verdad de la de justificación. Putnam, frente a la noción de la verdad como correspondencia, sostiene un concepto de verdad como "una especie de aceptabilidad racional (idealizada)" que, por desgracia, no precisa. La describe con características tan generales que pueden aplicarse a varias nociones de verdad. Se trata — dice- - de "una especie de coherencia ideal entre nuestros conceptos y con nuestras experiencias tal como son ellas mismas representadas en nuestro sistema de creencias" (1981, pp. 49-50).

Habermas parte de un supuesto que no se acompaña de suficiente argumentación: que la "pretensión de verdad" es una "pretensión justificada de validez" (berechtige Geltunganspruch). En consecuencia, da por supuesto que la verdad podría definirse en función de la justificación. "Llamamos vendaderos a los enunciados que podemos justificar”. Pero, como la justificación supone la coincidencia de predicaciones entre todos los sujetos, la verdad puede definirse como "promesa (Versprechen) 
de alcanzar un consenso racional" (1976, p. 219). Éste no es un concepto descriptivo de una situación de hecho, sino un concepto normativo. Para que se realice esa "promesa", es menester una situación de interacción comunicativa ideal (1976, p. 255). Luego, la verdad puede definirse en términos de una justificación bajo condiciones ideales.

Olivé, a su vez, sostiene una noción de vendad derivada de la de justificación objetiva universal. Mientras la justificación objetiva consistiría en la aceptabilidad para todo sujeto de una comunidad epistémica en el interior de un marco conceptual, la verdad sería la "aceptabilidad racional en condiciones epistémicas ideales", válidas, por lo tanto, para cualquier sujeto en el interior de cualquier marco conceptual (1984, pp. 95-101, 1986 , p. 179,1988 , p. 144).

Los tres autores comparten un supuesto: la vendad puede entenderse como un caso "ideal" de justificación objetiva. Ese supuesto me suscita dudas.

Me parece que "vendad" y "justificación" responden a preguntas diferentes. No podemos confundir la pretensión (Anspruch, claim) de verdad con la pretensión de justificación universal. La primera pretende que, si un enunciado es verdadero, el hecho enunciado es; la segunda, que nadie puede acceder a razones que invaliden lo bien fundado de un enunciado. La primera contesta a la pregunta iexiste $p$ realmente?, la segunda, a ¿esta " $p$ " justificada para cualquier sujeto? "Vendad" está emparentada con "realidad", "justificación" con "intersubjetividad". Que " $p$ " esté justificada objetivamente quiere decir que está basada en razones no controvertibles por otros sujetos, por lo tanto, que se refire a una situación válida para todos. Que " $p$ " sea verdadera quiere decir que lo enunciado forma parte del mundo real, independientemente de que otros sujetos coincidan en enunciarlo.

"Hecho" (Tatsache, fact) es lo que hace verdadera a una proposición. No es lo aseverado en condiciones ideales sino aquello que está allí, en el mundo real y que es aseverado. No 
se trata, claro está, de una realidad metafísica, ajena a toda interpretación, pero sí de una realidad que no es puesta por $\mathrm{mi}$ acto de enunciarla; de algo que se me impone a pesar de mis conceptos, con lo que me encuentro. En un sentido vivido, "realidad" no es una $x$ que existiera "fuera de mí", realidad es aquello que me resiste, se me opone, me hace frente, aquello que no es construido, fraguado, puesto por mí. Puedo pensar que el objeto de percepción no es meramente subjetivo en la medida en que reconozca en él un elemento dado, que se hace por sí mismo presente (Selbsgegeben). Cierto que sólo puede darse condicionado por mi aparato perceptivo y en el marco de mi estructura conceptual, pero no pretendería a la realidad del objeto percibido si no aprehendiera en él un elemento dado. En la práctica, al manipular los objetos, compruebo un factor de resistencia que se opone a mi acción voluntaria, sólo por ello, opongo a mi acción voluntaria una "realidad" que le hace frente. La primera noción de una realidad vivida se refiere a aquello que hace resistencia a mi deseo, aquello con lo que me encuentro, contradiciendo a menudo mis expectativas, lo que se impone y resiste. El concepto discursivo de "realidad" tiene que recoger esa vivencia originaria. En efecto, la presencia de lo dado en la percepción, la resistencia del objeto en la práctica no bastan para poder afirmar la realidad del objeto. Es menester pasar de la vivencia precrítica a un razonamiento que descarte las posibilidades de engaño o ilusión subjetivas. El juicio de realidad es resultado de una inferencia. Podremos juzgar "real" el hecho percibido o enunciado en la medida en que comprobemos que efectivamente está dado y no propuesto, que efectivamente se me impone y no es un producto más de mi deseo. Pero al inferir la realidad del hecho, simplemente afirmo que no ha sido fraguado por mí, sino que forma parte de esa esfera de lo impuesto a mis acciones, deseos y creencias. Lo que asevero es que en el hecho confluyen ("se corresponden") lo aseverado y lo presente o impuesto. 
Sin duda la reflexión nos muestra que los hechos reales sólo me salen al encuentro bajo ciertas condiciones subjetivas y en el marco de ciertas actitudes y conceptos. Pero eso no elimina que al decir "es verdad que $p$ " lo que pretendo es que $p$ se me impone, me sale al encuentro bajo esas condiciones y en ese marco. Cierto que "es verdad que $p$ " se infiere de " ' $p$ ' está objetivamente justificada". Pero esas dos proposiciones no tienen el mismo sentido. La primera dice: " $p$ forma parte del mundo real", la segunda dice: "cualquier sujeto de una comunidad epistémica, si se atiene a sus razones, aceptará la proposición " $p$ forma parte del mundo real" ".

Si la verdad se definiera como alguna forma de justificación objetiva o de "aceptabilidad" universal bajo ciertas condiciones, " ' $p$ ' es verdadera aunque no sea aceptable por todo sujeto en condiciones ideales" sería un enunciado contradictorio. Ahora bien, podemos sostener que ese enunciado es falso o que no está suficientemente justificado, pero no que sea contradictorio. Por ejemplo, si Meister Eckhart sostiene la verdad del enunciado "El fondo del yo es idéntico al fondo de la Deidad", no quiere obviamente decir que esa verdad sea "aceptable para todo sujeto racional"; por el contrario, él sabe bien que no es así, por que para aceptarla se requieren ciertas condiciones tanto intelectuales como emotivas. Lo que Eckhart quiere decir es que esa proposición expresa una realidad, independientemente de que alguien la acepte o no. Para justificar su aserto debe recurrir a razones _-en este caso, una experiencia mística privilegiada - que pueden o no coincidir con las nuestras. La aceptabilidad universal podría tener el estatuto de un criterio estricto de objetividad. Siguiendo ese criterio, podemos concluir que las razones aducidas por Eckhart no son objetivas. Lo cual permitiría sostener que Eckhart no sabe lo que afirma, sino sólo lo cree por razones subjetivas, pero no concluir que la proposición de Eckhart no exprese una creencia verdadera. No sólo el conocimiento místico —ejemplo extremo de creencias condicionadas por actitudes - sino todo conocimiento personal 
está en ese caso; y no podemos concluir por ello que no haya conocimiento personal verdadero. No es necesariamente falso que "la vida sea un continuo pesar" porque sólo unos cuantos aceptarían lo razonable de ese enunciado. En suma, la aceptabilidad racional en condiciones ideales puede ser un criterio estricto de objetividad pero no corresponde a lo que entendemos por verdad.

\section{Garantías de acierto}

Si la verdad no se define en términos de justificación objetiva ¿cuál sería la relación entre ambos términos? Sólo puede ser, me parece, una relación de inferencia. De los enunciados sobre las razones en que se basa " $p$ " podemos inferir " ' $p$ ' es verdadera". Pero esa inferencia nunca es infalible. Cabe siempre la posibilidad de creencias objetivamente justificadas en una comunidad epistémica que se revelen falsas ante razones suplementarias a que tenga acceso otra comunidad. Cabe también siempre la posibilidad de creencias de hecho verdaderas, pero no justificadas objetivamente. La justificación admite muchos grados pero nunca - aun en condiciones ideales - coincide con la verdad misma.

En los "conocimientos personales" (Villoro, 1982), que no se acompañan de justificación objetiva, el darse mismo del objeto o situación objetiva en una experiencia justifica una presunción de su verdad, aunque no suministre una garantía firme de lograrla. De hecho, el darse de la cosa misma se acompaña regularmente de una creencia espontánea en su existencia real. Tomar las cosas mismas "tal como se dan y en los límites en que se dan", según el lema fenomenológico, constituye una condición de una predicación justificada de verdad. Por ello se comprende que Husserl haya hablado de una "verdad antepredicativa". Pero esa expresión es impropia. En efecto, el propio Husserl admitió que la evidencia ante-predicativa debe someterse a crítica antes de aceptarse como justificación de una 
predicación verdadera. La presencia de lo dado por sí mismo es una condición necesaria pero no suficiente de verdad. Sólo si tenemos razones para aseverar que lo dado no está sometido a circunstancias que lo distorsionan ni nosotros somos víctimas de un engaño, podemos razonablemente pretender su verdad. En los conocimientos personales, desprovistos de razones objetivamente suficientes, una afirmación de verdad es la conclusión de: 1. Enunciados que aseveran la presencia de algo que se da por sí mismo. 2. Enunciados que descartan la existencia de circunstancias que distorsionarían esa presencia revelándola como una ilusión o engaño. Ésta no es una justificación objetiva. Sin embargo, en nuestras creencias no científicas, es razonable inferir de ella que lo dado corresponde a una realidad. No sería, en cambio, razonable pretender que constituye una garantía de acierto, aceptable por cualquier miembro de una comunidad epistémica determinada.

Llegamos así a la noción, un tanto metafórica, de "garantía". La justificación objetiva es garantía de verdad y, como ésta permite el acierto en la acción, es también garantía de acierto. La garantía de verdad es —como indicaba Platón— una "atadura con la realidad". Nos vincula a ella de manera firme. Pero, por firme que sea, toda atadura puede ser desecha. La posesión de una credencial garantiza ante los demás la membresía a una institución. Pero ellos no tienen acceso directo a esa membresía. Sólo pueden inferirla de la credencial. Y ésta, en su límite, podría estar falsificada. La palabra de $S$ ofrece una garantía de que $Z$ cumplirá. Pero por honorable que sea $S$, podría faltar a su palabra. Garantizar algo es anudarlo, tenerlo por seguro; pero todo nudo puede romperse. Los nudos son más o menos fuertes. En un caso extremo, pueden ser tan sólidos que su ruptura es difícilmente concebible, pero siempre es lógicamente posible. Es el caso de la "justificación objetiva". Sólo si tuviéramos acceso a la verdad, sin mediación de razones, la "atadura" a la realidad sería irrompible. Pero esto sería inadmisible, me parece, para el propio Olivé. 
Olivé distingue, con acierto, entre dos sentidos de "garantía": garantía como "confianza" y garantía como seguridad objetiva, independiente de la convicción subjetiva. Pero me parece que no está en lo justo al identificar la segunda con "la verdad de las proposiciones, esté o no el sujeto al tanto de esa verdad" (1984, p. 165, 1988, p. 149). Olivé admite, en efecto, que la objetividad de la justificación, en el interior de una comunidad epistémica, es garantía de acierto para cualquier sujeto de esa comunidad, pero piensa que puede haber situaciones en que, para un observador externo a esa comunidad, la garantía ya no sea la objetividad sino "la verdad misma". Aduce, para mostrar su punto, un ejemplo. Supongamos, dice, por una parte las creencias de una comunidad justificadas para todo miembro de esa comunidad; por el otro lado, un observador, ajeno a esas creencias, perteneciente, por lo tanto, a otra comunidad epistémica, que comprobara la verdad de esas creencias, pero recusara las justificaciones que los miembros de aquella comunidad les daban. En ese caso, concluye Olivé, para el observador, la garantía de acierto de la comunidad observada no pueden ser sus justificaciones sino "la verdad de las proposiciones" (1984, p. 165, 1988, p. 148). Me parece, sin embargo, que el análisis que da Olivé de su ejemplo no es convincente. En efecto, supongamos el caso de dos sujetos $S$ y $S^{\prime}$, pertenecientes a sendas comunidades epistémicas, $C$ y $C^{\prime}$, diferentes. $S^{\prime}$ sería el observador externo del ejemplo de Olivé. $S^{\prime}$ puede juzgar verdaderas las proposiciones formuladas por $S$, aunque no comparta sus razones. Pero, para ello, $S^{\prime}$ tiene que dar otras razones accesibles a su propia comunidad epistémica $\left(C^{\prime}\right)$ que no eran accesibles a $S$. La garantía de acierto para $S^{\prime}$ es su propia justificación, que rebasa las razones accesibles a la comunidad a que pertenece $S$. Porque $S^{\prime}$ (el observador del ejemplo de Olivé) puede acceder a razones suplementarias, a las que $S$ no tiene acceso, puede juzgar, tanto de la verdad de la proposición formulada por $S$ como de la falsedad de sus razones. Entonces la garantía de acierto para $S^{\prime}$ no es la ver- 
dad misma sino una nueva justificación objetiva, basada en las razones accesibles a $C^{\prime}$. A la verdad misma no tiene acceso directo $S^{\prime}$ como tampoco lo tenía $S$, sino sólo al través de las razones dentro de su propio marco conceptual.

\section{Aceptabilidad racional}

Los intentos de comprender la verdad en términos de condiciones que sirven para definir la justificación objetiva me parecen enfrentarse a varias dificultades. Es el caso de la verdad como "aceptabilidad racional en condiciones epistémicas ideales" según la formulación de Olivé (1988, p. 144, 1984, p. 100, 1986, p. 179).

1. Si la verdad se define en términos de aceptabilidad por cualquiera y ésta implica racionalidad, entonces sólo serían verdaderas las proposiciones justificadas racionalmente ante cualquier sujeto. Luego, sería contradictorio "creo que 'p' es verdadera pero no es justificable para cualquier sujeto". Sin embargo, ese enunciado puede ser falso, pero no es contradictorio. De hecho, la mayoría de nuestras creencias son de ese tipo. Tenemos por verdaderas muchas proposiciones que expresan convicciones profundas y no pretendemos que sean universalmente aceptables. Es el caso de la mayoría de nuestras creencias morales, políticas, estéticas o religiosas.

2. Una definición semejante de verdad comprometería a una posición racionalista extrema. Sólo estaríamos en el derecho de considerar verdadero lo demostrable racionalmente mediante procedimientos argumentativos válidos universalmente. Tendríamos que rechazar como falsa $\longrightarrow$, al menos, como irracional - toda creencia que no fuera racional según los criterios más estrictos. Nos comprometeríamos entonces a reducir cualquier creencia, moral, política o religiosa, con pretención de verdad, a requisitos de una racionalidad estricta. ¿No es un hecho, sin embargo, que los programas de vida, las apuestas comunitarias que afirman valores, los juicios morales o religio- 
sos basados en experiencias personales pueden pretender la verdad sin por ello comprometerse a una aceptabilidad universal?

3. Entendemos que la aceptabilidad racional bajo condiciones ideales no es un concepto descriptivo de una situación de hecho. Respecto de su definición paralela de "verdad" como consenso bajo condiciones ideales de racionalidad, Habermas indica que se trata de un concepto normativo (1973, p. 239). Me parece que la noción de verdad de Olivé tendría que tener un estatus semejante. No podemos pues alegar en su contra su irrealidad, pero sí su pertinencia. ¿Una situación de consenso basada en argumentaciones discursivas puramente racionales es realmente deseable? Todo interlocutor en esa situación ideal tendría que dejar de lado cualquier motivación personal y sólo aceptar razones objetivas válidas universalmente. Se obligaría a un discurso ascético del que habría desaparecido cualquier interferencia de las actitudes emotivas en la aceptación de creencias. Ahora bien, es cierto que las motivaciones personales son el principal obstáculo en el acceso a una justificación objetiva, pero es cierto también que, en muchos campos, la prosecución de la verdad no puede darse sin una actitud personal de carácter emotivo. La pasión por la justicia, por la realización personal, el amor y la compasión, el anhelo mismo de verdad ¿no son acaso necesarios en la empresa de alcanzar la realidad más allá de nuestros intereses individuales? ¿Y son esas pasiones reducibles a motivaciones racionales, compartibles por cualquiera? La sola pregunta muestra, al menos, la dificultad de la respuesta.

Parece plausible el programa de Habermas: determinar las condiciones de posibilidad de una interacción comunicativa que permitiera una comunicación tal que cada quien pudiera sostener la verdad de ciertos programas de vida dirigidos a la realización de valores. Pero entonces las verdades así sostenidas no son equivalentes a las condiciones de su posibilidad. La meta no es igual al camino. 
4. Parece difícil determinar cuáles serían las "condiciones ideales" para una comunicación racional. Olivé sostiene que se llegaría a ellas "por un intercambio racional". Tal vez. Pero quizás fueran necesarias también otras condiciones subjetivas, que difícilmente llamaríamos "racionales", al menos en el mismo sentido, como: ruptura de los intereses egoístas, amor a la verdad, autenticidad, deseo del bien común, etc. $\mathrm{O}$ bien todas las condiciones para una interacción comunicativa ideal no son reducibles a una racionalidad discursiva, como la define Habermas, o bien nos comprometemos a suministrar un concepto de "racionalidad" mucho más amplio, que abarcara las motivaciones (actitudes personales) que mencionamos.

5. Dadas las dificultades señaladas ¿̇conviene definir la verdad a partir de la aceptabilidad racional o tratar de explicar la aceptabilidad racional por los conceptos más primitivos de realidad y de verdad? En Creer, saber, conocer intenté esta segunda vía. Olivé ha tenido razón en señalar las dificultades a que tiene que hacer frente. Pero creo que todas ellas provienen de interpretarla como un "realismo metafísico" y de aceptar una versión simplista, ligada a él, de la verdad como correspondencia. Rechazadas ambas tesis, me parece que esa vía es aún la más prometedora. Las críticas de Olivé al "realismo metafísico" y su propia concepción de un "realismo interno", lejos de clausurarla, serían una contribución importante para precisarla.

\section{REFERENCİAS BIBLIOGRÁFICAS}

Habermas, J., 1973, "Wahrheitstheorien" en Wirklichkeit und Reflexion: Festschrift für Walter Schulz, Pfullingen.

Husserl, E., 1929, Investigaciones lógicas, Rev. de Ocoidente, Madrid.

Olivé, L., 1984, “Villoro: sobre verdad, objetividad y saber", en Crítica, Vol. XVI, Núm. 48, México. 
- 1986, “Dos concepciones de verdad y sus relaciones con la teoría social", en Revista Latinoamericana de Fulosofia, Vol. XII, Núm. 2, Buenos Aires.

—, 1988, Conocimiento, sociedad y realidad, FCE, México.

Putnam, H., 1981, Reason, Truth and History, Cambridge Univ. Press.

Strawson, P., 1964, "Truth", en S. Pitcher (ed.), Truth, Prentice-Hall. Villoro, L., 1982, Creer, saber, conocer, Siglo XXI, México.

Recibido: 13 febrero 1900. 